\title{
Radiological survey of men exposed to asbestos in naval dockyards
}

\author{
P. G. HARRIES, F. A. F. MACKENZIE, G. SHEERS, J. H. KEMP, \\ T. P. OLIVER, and D. S. WRIGHT \\ Medical Research Unit, H.M. Dockyard, Devonport; Radiological Department, Royal Naval \\ Hospital, Plymouth; Plymouth Chest Clinic, Beaumont House, Plymouth; and \\ H.M. Dockyards Chatham, Rosyth, and Portsmouth
}

\begin{abstract}
Harries, P. G., Mackenzie, F. A. F., Sheers, G., Kemp, J. H., Oliver, T. P., and Wright, D. S. (1972). Brit. J. industr. Med., 29, 274-279. Radiological survey of men exposed to asbestos in naval dockyards. Asbestos related abnormalities were found in $3 \%$ of a $10 \%$ sample population in radiological surveys of the naval dockyards at Portsmouth, Chatham, and Rosyth. The prevalence of these abnormalities was related to the type of occupation and duration of exposure to asbestos. The results confirm the findings of an earlier survey at Devonport dockyard.

No association between smoking, or the amount smoked, and the incidence of parenchymal or pleural disease due to asbestos was detected.

Pleural abnormalities were found 10 times more frequently than parenchymal disease, and concern is felt over the uncertainty of the prognosis in men with pleural abnormalities, especially as 37 men have developed pleural mesothelioma at Devonport since 1965.

More work is required to establish the true significance of pleural abnormalities caused by asbestos and to explore possible methods of treatment.
\end{abstract}

The radiological survey of Devonport dockyard workers (Sheers and Templeton, 1968) has now been extended to the other three naval dockyards at Chatham, Portsmouth, and Rosyth. The results of the Devonport survey emphasized the extent of the problems associated with the use of asbestos in one naval dockyard and gave added impetus to the complete reassessment of the use of asbestos materials, and of working methods involving asbestos, in all naval dockyards which has been carried out by the Ministry of Defence (Navy) (Harries, 1968, 1971).

\section{Methods}

The methods used in this survey were the same as those used by Sheers and Templeton (1968).

The sample consisted of every tenth man on the staff and weekly paid payrolls of Portsmouth, Chatham, and Rosyth dockyards. Only female employees and male finance department employees were excluded because they were not exposed to asbestos. There were 2568 men in the sample and $2442(95 \%)$ of these were examined.

The medical departments of each dockyard supervised the completion of a short questionnaire on occupational history, smoking habits, and details of past illnesses from each subject at the time of the chest radiograph. The $100 \mathrm{~mm}$ chest photofluorographs were produced by an Odelca camera with stationary grid coupled to a $200 \mathrm{~mA}$ $x$-ray generator and phototimer.

The $100 \mathrm{~mm}$ films were read independently by three readers (P.G.H., F.A.F.M., and G.S.) and subjects were recalled for large films if any reader suspected an abnormality. Clinical examination of the chest was performed by dockyard medical officers for each recalled subject and included the completion of the Medical Research Council long respiratory symptoms questionnaire and the measurement of forced vital capacity (FVC) and one-second forced expiratory volume $\left(F_{E V} \mathbf{1}_{1 \cdot 0}\right)$ using a Vitalograph. When pulmonary fibrosis was suspected more detailed lung function examinations were undertaken at respiratory physiology laboratories. 


\section{Classification of radiographs}

The full-size postero-anterior and $45^{\circ}$ oblique radiographs of recalled subjects were read independently by the three film readers who also considered data from the respiratory questionnaire, clinical examination, and tests of ventilatory capacity before classifying the film. Differences between readers on the assessment of films were discussed and an agreed reading was produced for each film.

The $45^{\circ}$ oblique radiograph was useful in confirming or excluding the minor degrees of pleural thickening suspected on postero-anterior films (Mackenzie and Harries, 1970).

For the purpose of this survey minor degrees of parenchymal abnormality suggestive of early pulmonary fibrosis were noted but were not classified as being abnormal. Films were classified as showing evidence of pulmonary fibrosis only when there was supporting clinical and physiological evidence.

Pleural abnormalities were classified as being associated with asbestos only when other causes such as past infection, surgery, or trauma had been excluded. The types of asbestos pleural abnormalities were subdivided into limited or extensive pleural thickening and calcified or non-calcified pleural lesions.

\section{Results}

The new work reported in this paper relates to Chatham, Portsmouth, and Rosyth dockyards, but because the techniques used are the same as those used at Devonport by Sheers and Templeton (1968), the results are comparable and, as far as possible, the four dockyards are considered together.

Analysis of the questionnaires showed that there were no big differences between the dockyards in the age or occupational structure of the population, and that the proportions of men in each smoking category were similar for each yard.

\section{Radiological abnormalities}

The overall prevalence of asbestos abnormalities in the dockyards was $3 \cdot 16 \%$ (Table 1 ). The rates at Chatham and Portsmouth were slightly lower, and at Rosyth considerably lower, than at Devonport.

Pulmonary fibrosis (asbestosis) was suspected on the radiographs and confirmed by clinical and physiological examination in two men at Chatham, in three at Portsmouth, and in three at Rosyth. The men at Chatham and Rosyth were 'neighbourhood workers', their trades being engine fitter and electrical fitter (Chatham) and a skilled labourer, shipwright, and joiner (Rosyth). Two of the Portsmouth men were laggers, and the third was a retired Royal Navy engine room artificer working as an engine fitter.

Five of the eight men had been employed at their trades for more than 25 years, and none for less than 15 years. Only one man had less than 25 years elapsed time from his first exposure to asbestos. One man in each dockyard had radiological pleural abnormalities in addition to the parenchymal changes.

Four cases of pulmonary fibrosis were found in the sample population at Devonport in 1968. Three of them were laggers, and they had been exposed to asbestos dust for more than 15 years. The fourth man had been intermittently exposed to asbestos dust for 29 years, during which time he was periodically employed in cleaning up asbestos debris in ships.

Sixty-one of the 69 men with asbestos abnormalities had pleural changes. Limited plaques occurred more frequently than extensive pleural abnormalities and more non-calcified than calcified lesions were seen (Table 2). These findings are similar to those in the Devonport study.

Other radiographic abnormalities were recorded in $119(44.2 \%)$ of the 269 men recalled for large films in Chatham, Portsmouth, and Rosyth. These abnormalities included extensive healed pulmonary tuberculosis, unilateral pleural fibrosis resulting from empyema, and abnormalities associated with extensive surgical treatment. There were many radiographs with increased basal lung markings and some of these men had a history of chronic bronchitis and emphysema. Simple tests of ventilatory capacity showed the predominance of airways obstructive disease in this group.

No cases of pleural mesothelioma were recorded in the sample populations even though they have

TABLE 1

Overall Prevalence of Radiographic Asbestos Abnormalities

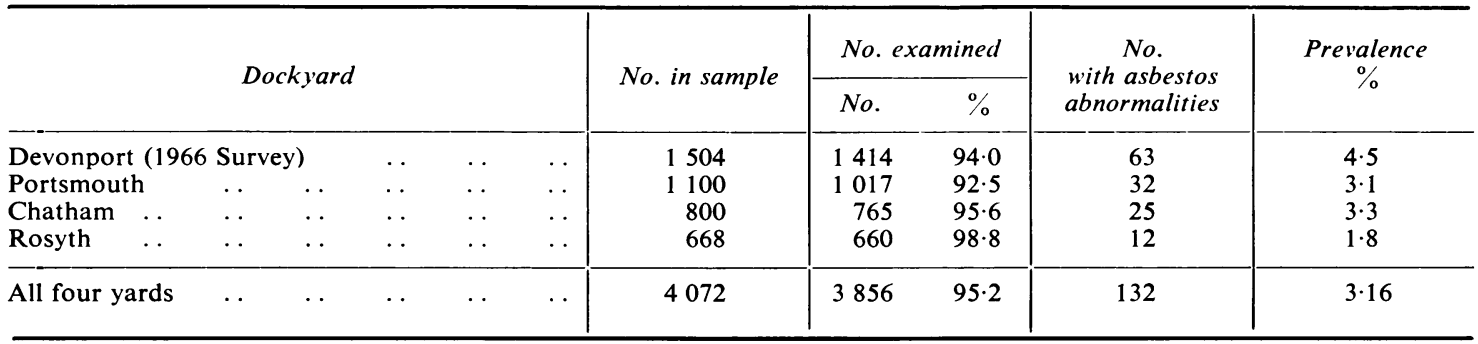


TABLE 2

Radiographic Asbestos AbNormalities

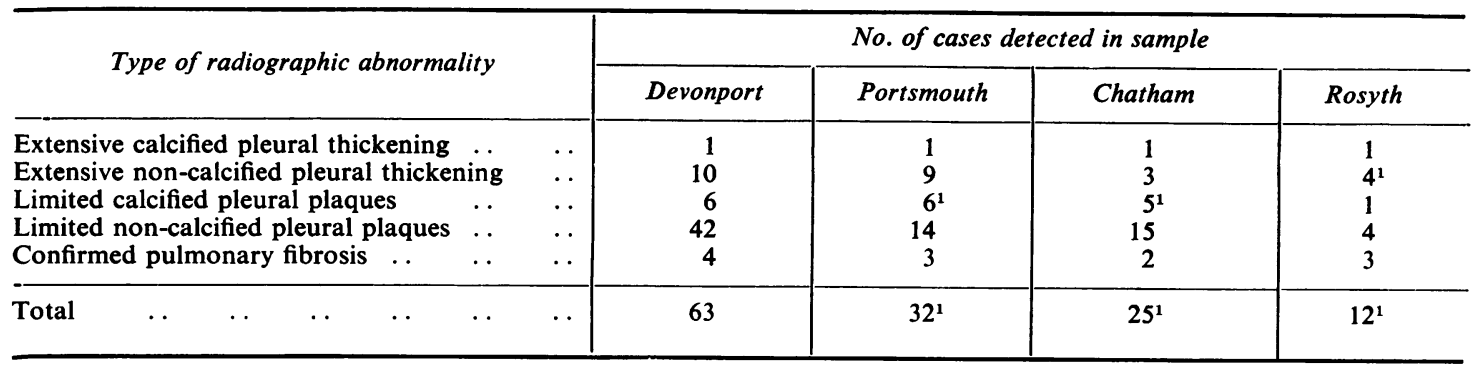

${ }^{1}$ One man also had pulmonary fibrosis, confirmed by clinical and lung function examination.

been reported in men from Devonport, Chatham, and Portsmouth dockyards. The reasons for not detecting such cases in the 1 in 10 sample are that the incidence of this tumour is small and that persons suffering from the disease would probably not be at work.

At Devonport there have been 37 cases of pleural mesothelioma in dockyard workers since 1965 , and in 10 of these cases bilateral non-calcified pleural plaques were present on series of chest radiographs taken before the development of the tumour. The remaining 27 cases presented with large pleural tumours with or without pleural effusions. Previous films were either normal (9) or there were no available previous films (18).

\section{Smoking}

There was no definite evidence in these surveys to suggest that asbestos abnormalities occurred more frequently in men who smoked most heavily (Table 3). Men who admitted smoking at least $25 \mathrm{~g}$ of tobacco daily and those who had given up smoking showed the highest rates of radiological abnormalities associated with other diseases.

\section{Lung function}

The tests of ventilatory capacity performed in these surveys on most men recalled for large films showed that men with pulmonary fibrosis tended to have restrictive ventilatory defects; those with pleural abnormalities had normal values. Men with other diseases showed an obstructive ventilatory pattern with the $\mathrm{FEV}_{1 \cdot 0}$ reduced proportionately to a greater extent than the FVC.

Because this survey was essentially based on radiological appearances these tests were merely used as clinical screening aids, and more comprehensive lung function assessment was confined to those men who were suspected of having developed pulmonary fibrosis. Pulmonary fibrosis was confirmed when basal rales were present and when lung function tests showed a restriction of static and dynamic lung volumes with a low transfer factor.

\section{Effects of occupation}

Sheers and Templeton (1968) grouped the various dockyard trades in an attempt to subdivide the population into four grades of intensity of asbestos exposure. In order to make comparisons between

TABLE 3

Radiographic Abnormality and Smoking Habits (Portsmouth, Chatham, Rosyth) (not recorded at Devonport)

\begin{tabular}{|c|c|c|c|c|c|c|c|}
\hline & & \multirow{2}{*}{$\begin{array}{l}\text { Non- } \\
\text { smokers }\end{array}$} & \multirow{2}{*}{$\begin{array}{c}\text { Ex- } \\
\text { smokers }\end{array}$} & \multicolumn{4}{|c|}{$\begin{array}{c}\text { Smoking categories: average daily tobacco } \\
\text { consumption }\end{array}$} \\
\hline & & & & $1-4 g$ & $5-14 g$ & $15-24 g$ & $25 g+$ \\
\hline $\begin{array}{l}\text { No. of men } \ldots \\
\text { No. of asbestos abnormalities } \\
\text { Rate } \ldots \\
\text { No. of other abnormalities } \\
\text { Rate } .\end{array}$ & $\begin{array}{l}\cdots \\
\cdots \\
\cdots \\
\cdots\end{array}$ & $\begin{array}{l}808 \\
20 \\
2.5 \% \\
85 \\
10.5 \%\end{array}$ & $\begin{array}{l}54 \\
0 \\
0 \\
11 \\
20 \cdot 4 \%\end{array}$ & $\begin{array}{l}123 \\
3 \\
2 \cdot 4 \% \\
13 \\
10 \cdot 6 \%\end{array}$ & $\begin{array}{l}400 \\
14 \\
3.5 \% \\
44 \\
11.0 \%\end{array}$ & $\begin{array}{l}1011 \\
32 \\
3.2 \% \\
120 \\
11.9 \%\end{array}$ & $\begin{array}{l}47 \\
0 \\
0 \\
8 \\
17 \cdot 0 \%\end{array}$ \\
\hline
\end{tabular}


the yards we used the same classification (Table 4). In each yard those groups thought to have been exposed to higher concentrations of dust showed more asbestos related abnormalities than the groups with lesser dust exposure.

The prevalence of asbestos abnormalities is highest in men heavily and continuously exposed to asbestos (group I asbestos sprayers and laggers), but the results show that there are other occupations in which the rates are higher than in the general dockyard population. The numbers of affected men in individual trades are small so that it is unwise to draw firm conclusions from this survey, but the results suggest that joiners, painters, riveters, caulkers, drillers, shipwrights, engine fitters, and men who had been employed for most of their working life as Royal Navy engine room artificers have higher than average prevalence rates. Joiners have been exposed to dust by working with asbestos sound insulation, and painters because of their association with asbestos spraying, but most of the remaining 'high risk' groups are 'neighbourhood workers' in engine rooms and boiler rooms where insulating work has been undertaken by others.

It was thought that pulmonary fibrosis (asbestosis) might be limited to those men continuously working with asbestos (group I occupations), but more than half of the men with pulmonary fibrosis discovered in the present survey were 'neighbourhood workers'. Experience from all dockyard employees at Devon- port confirms the sample findings; only 41 of the 128 men who have disability pensions for asbestosis are recognized asbestos workers.

Pleural abnormalities were found more frequently than the parenchymal disease and they give rise to concern not only because of the larger numbers of men affected, but also because of the uncertainty of the prognosis. There is some evidence to suggest that pleural abnormalities are associated with changes in lung function (Becklake et al., 1970; Harries, 1970c) but the simple tests of ventilatory function carried out in these surveys showed only that pulmonary fibrosis was associated with a restrictive lung defect, and that other chronic lung conditions were accompanied by an obstructive pattern of lung function.

Extensive pleural fibrosis is associated with a reduced lung volume and ventilatory capacity and can cause physical disability. Measurement of static and dynamic lung volumes and transfer factor in 11 men with extensive pleural thickening identified in the Devonport sample (Sheers and Templeton, 1968) shows that for all 11 men the FVC and FEV 1.0 were less than the predicted normal values and the transfer factor was less than the predicted value in 10 of them (Table 5). Predicted values for FVC, $\mathrm{FEV}_{1 \cdot 0}$, total lung capacity, and transfer factor were calculated from the regression equations from Cotes (1968). These data form part of a more detailed study of men with asbestos pleural abnormalities presently being undertaken at Devonport.

TABLE 4

Prevalence of Asbestos Abnormalities in Occupational Groups

\begin{tabular}{|c|c|c|c|c|c|c|c|c|c|}
\hline \multirow{3}{*}{ Trade } & \multirow{3}{*}{ Group } & \multicolumn{8}{|c|}{ Dockyard } \\
\hline & & \multicolumn{2}{|c|}{ Portsmouth } & \multicolumn{2}{|c|}{ Chatham } & \multicolumn{2}{|c|}{ Rosyth } & \multicolumn{2}{|c|}{ Devonport } \\
\hline & & Examined & Abnormal & Examined & Abnormal & Examined & Abnormal & Examined & Abnormal \\
\hline $\begin{array}{l}\text { Lagger, sprayer, } \\
\text { mason, sailmaker- } \\
\text { lagger, painter, } \\
\text { asbestos storeman }\end{array}$ & I & 49 & $6(12 \%)$ & 24 & $1(4 \%)$ & 10 & $1(10 \%)$ & 42 & $15(36 \%)$ \\
\hline $\begin{array}{l}\text { Electrical fitter, } \\
\text { burner, welder, } \\
\text { riveter, caulker, } \\
\text { driller, shipfitter, } \\
\text { plumber, copper- } \\
\text { smith .. }\end{array}$ & II & 213 & $9(4 \%)$ & 168 & $6(4 \%)$ & 179 & $3(2 \%)$ & 355 & $22(6 \%)$ \\
\hline $\begin{array}{l}\text { Shipwright, engine } \\
\text { fitter } \quad \ldots \quad \quad \ldots\end{array}$ & III & 220 & $7(3 \%)$ & 170 & $6(4 \%)$ & 139 & $5(4 \%)$ & 333 & $12(4 \%)$ \\
\hline $\begin{array}{c}\text { All other occupa- } \\
\text { tions } \quad \ldots\end{array}$ & IV & 535 & $10(2 \%)$ & 403 & $12(3 \%)$ & 332 & $3(1 \%)$ & 684 & $14(2 \%)$ \\
\hline Total & & 1017 & $32(3 \cdot 1 \%)$ & 765 & $25(3 \cdot 3 \%)$ & 660 & $12(1.8 \%)$ & 1414 & $63(4.5 \%)$ \\
\hline
\end{tabular}


TABLE 5

Lung Volumes and Gas Transfer in 11 Men with Extensive Pleural Thickening

\begin{tabular}{|c|c|c|c|c|c|c|c|c|}
\hline \multirow{2}{*}{\multicolumn{3}{|c|}{ Index }} & & \multicolumn{2}{|c|}{ Actual } & \multicolumn{2}{|c|}{ Predicted } & \multirow{2}{*}{$\mathbf{P}$} \\
\hline & & & & Mean & $S D$ & Mean & $S D$ & \\
\hline $\begin{array}{l}\text { FEV }_{1 \cdot 0}(1 . \text { BTPS) } \\
\text { FVC (1. BTPS) } \\
\text { TLC (1. BTPS) } \\
\text { TF (single breath) }\end{array}$ & $\begin{array}{ccc}\cdots & \cdots & \cdots \\
\cdots & \cdots & \cdots \\
\ddot{(m l C O} / \mathrm{min} / \mathrm{mm} \mathrm{Hg})\end{array}$ & $\begin{array}{l}\cdots \\
\cdots \\
\cdots\end{array}$ & $\begin{array}{l}\cdots \\
\cdots \\
\cdots \\
\cdots\end{array}$ & $\begin{array}{r}2 \cdot 09 \\
3 \cdot 13 \\
5 \cdot 71 \\
19 \cdot 04\end{array}$ & $\begin{array}{l}0 \cdot 63 \\
0 \cdot 60 \\
0 \cdot 51 \\
4 \cdot 71\end{array}$ & $\begin{array}{r}2 \cdot 91 \\
3 \cdot 93 \\
6 \cdot 31 \\
24 \cdot 32\end{array}$ & $\begin{array}{l}0 \cdot 37 \\
0.44 \\
0 \cdot 66 \\
3 \cdot 06\end{array}$ & $\begin{aligned}< & 0.001 \\
< & 0.001 \\
& 0.01 \\
& 0.0025\end{aligned}$ \\
\hline
\end{tabular}

\section{Duration of exposure}

The Devonport study showed that there was a long interval between first exposure to asbestos and the detection of radiographic asbestos abnormalities, and similar results were seen in the other three yards. In $54(78 \%)$ of the 69 affected men more than 25 years had elapsed since their first exposure to asbestos, and $46(67 \%)$ of the 69 men had worked with or near asbestos for 25 years or more. The overall prevalence of asbestos abnormalities for men with more than 25 years since first exposure to asbestos was $8.1 \%$ (Table 6). The rate was higher in Devonport but similar in the other three yards.

\section{Discussion}

The results of these surveys confirm that asbestos related abnormalities of the lungs and pleura are occurring in the employees at naval dockyards in Portsmouth, Chatham, and Rosyth as well as at Devonport. The prevalence rates are based on relatively small numbers of affected men, but on good representative samples with a very low lapse rate. Thus different rates in the four yards probably reflect the true situation in the total population of each. Sheers and Templeton (1968) suggested that 600 men at Devonport dockyard might be expected to show evidence of asbestos disease, and, since 1965, there have been 128 cases of asbestosis at Devonport accepted for disability pensions by the Pneumoconiosis Medical Panel; 37 men have developed pleural mesothelioma, and over 500 other dockyard employees show evidence of pleural fibrosis or calcification.

The high rates at Devonport may be the result of the type of refitting work involving the largest aircraft carriers at that yard, while the low rates at Rosyth are probably related to the small number of extensive refits of surface ships undertaken there in the last 25 years.

It is disturbing that more than half the cases of pulmonary fibrosis (asbestosis) and pleural abnormalities related to asbestos exposure were found in so-called 'neighbourhood workers' who have not themselves worked regularly with asbestos products. The explanation lies in the widespread contamination of ships during lagging and spraying involving asbestos insulating materials (Harries, 1971). At Devonport all of the dockyard cases of pleural mesothelioma are in neighbourhood workers; none in recognized asbestos workers. A similar observation has been made by Stumphius (1971) in his report on shipyard workers in the Netherlands.

Selikoff, Hammond, and Churg (1968) suggested that men exposed to asbestos as insulation workers who also smoke are at greater risk of developing bronchial carcinoma than non-smokers. Radiological abnormalities associated with asbestos in the population of the present survey do not appear to be associated with smoking habits. The samples showed that the smoking habits of dockyard employees are similar to those of the general population, and a mortality study of Plymouth men has indicated that at present there is no evidence to suggest an

TABLE 6

Prevalence of Asbestos Abnormalities in Men with 25 Years or More since FIRST EXPOSURE

\begin{tabular}{ll|c|c|c|c|c|c|c|c}
\hline & & \multicolumn{4}{|c|}{ Occupational group four dockyards } & \multicolumn{3}{c}{ Dockyard-all occupations } \\
\cline { 3 - 9 } & & I & II & III & IV & Portsmouth & Chatham & Rosyth & Devonport \\
\hline No. examined &. & 63 & 250 & 249 & 606 & 364 & 254 & 144 & 406 \\
No. abnormal &. & 15 & 26 & 23 & 30 & 21 & 18 & 10 & 45 \\
Prevalence &. & $24 \%$ & $10 \%$ & $9 \%$ & $5 \%$ & $6 \%$ & $7 \%$ & $7 \%$ & $11 \%$ \\
\hline
\end{tabular}


excess mortality from lung or gastrointestinal cancers in dockyard employees (Harries, 1970d).

In an attempt to answer many current uncertainties about asbestos related diseases a research programme is being prepared by the Institute of Naval Medicine (for Ministry of Defence (Navy)) and the Medical Research Council Pneumoconiosis Unit. The work will include a radiographic survey of the total population in each naval dockyard, together with more detailed studies of selected groups of men with asbestos abnormalities, or in specified occupational groups. The detailed studies will include physiological and immunological investigations and will be linked with other research into possible methods of treatment of diseases caused by asbestos.

\section{Conclusions}

New cases of asbestos disease may be expected to occur in naval dockyard employees for many years despite the preventive measures introduced to prevent extensive contamination of ships by harmful concentrations of asbestos dust. There are men in each dockyard with undetected asbestos disease, and there are apparent differences in the prevalence of these diseases between the dockyards. The prognosis of men with asbestos pleural disease is uncertain, and increasing numbers of pleural mesothelioma are occurring in dockyard workers.

This work has been supported jointly by the Ministry of Defence (Navy) and the Medical Research Council. The clinical examinations were carried out by Surgeon Lieutenant Commander D. S. Wright (Portsmouth) and Surgeon Lieutenants R. D. Cole (Rosyth) and J. G. Munro (Chatham). We are indebted to $\mathrm{Dr}$ L. H. Capel of the London Chest Hospital and Dr G. J. R. McHardy of the City Hospital at Edinburgh for detailed lung function examination of some of the subjects. We are grateful for the skilled work of the staff of the Plymouth Mass Radiography Unit for the $100 \mathrm{~mm}$ films, and of the Royal Navy radiographers at each port for the large films. We thank the Admiral Superintendents and staff of each dockyard for their co-operation; and the Medical Director General (Naval) for his permission to publish this report.

\section{References}

Becklake, M. R., Fournier-Massey, G., McDonald, J. C., Siemiatycki, J., and Rossiter, C. E. (1970). Lung function in relation to chest radiographic changes in Quebec asbestos workers. Bull. physiopath. resp., 6, 637-659.

Cotes, J. E. (1968). Lung Function, 2nd ed., pp. 374-375. Blackwell, Oxford.

Harries, P. G. (1968). Asbestos hazards in Naval Dockyards. Ann. occup. Hyg., 11, 135-145.

(1970a). The effects and control of diseases associated with exposure to asbestos in a Naval Dockyard. London M.D. thesis, pp. 54-84. (1970b). Ibid., pp. 98-111. (1970c). Ibid., pp. 140-240. (1970d). Ibid., pp. 285-295.

_ (1971). Asbestos dust concentrations in ship repairing: A practical approach to improving asbestos hygiene in Naval Dockyards. Ann. occup. Hyg., 14, 241-254.

Mackenzie, F. A., and Harries, P. G. (1970). Changing attitudes to the diagnosis of asbestos disease. J. roy. Nav. med. Serv., 56, 116-123.

Selikoff, I. J., Hammond, E. C., and Churg, J. (1968). Asbestos exposure, smoking and neoplasia. J. Amer. med. Ass., 204, 106-112.

Sheers, G., and Templeton, A. R. (1968). Effects of asbestos in dockyard workers. Brit. med. J., 3, 574-579.

Stumphius, J. (1971). Epidemiology of mesothelioma on Walcheren Island. Brit. J. industr. Med., 28, 59-66.

Received for publication August 10, 1971. 